
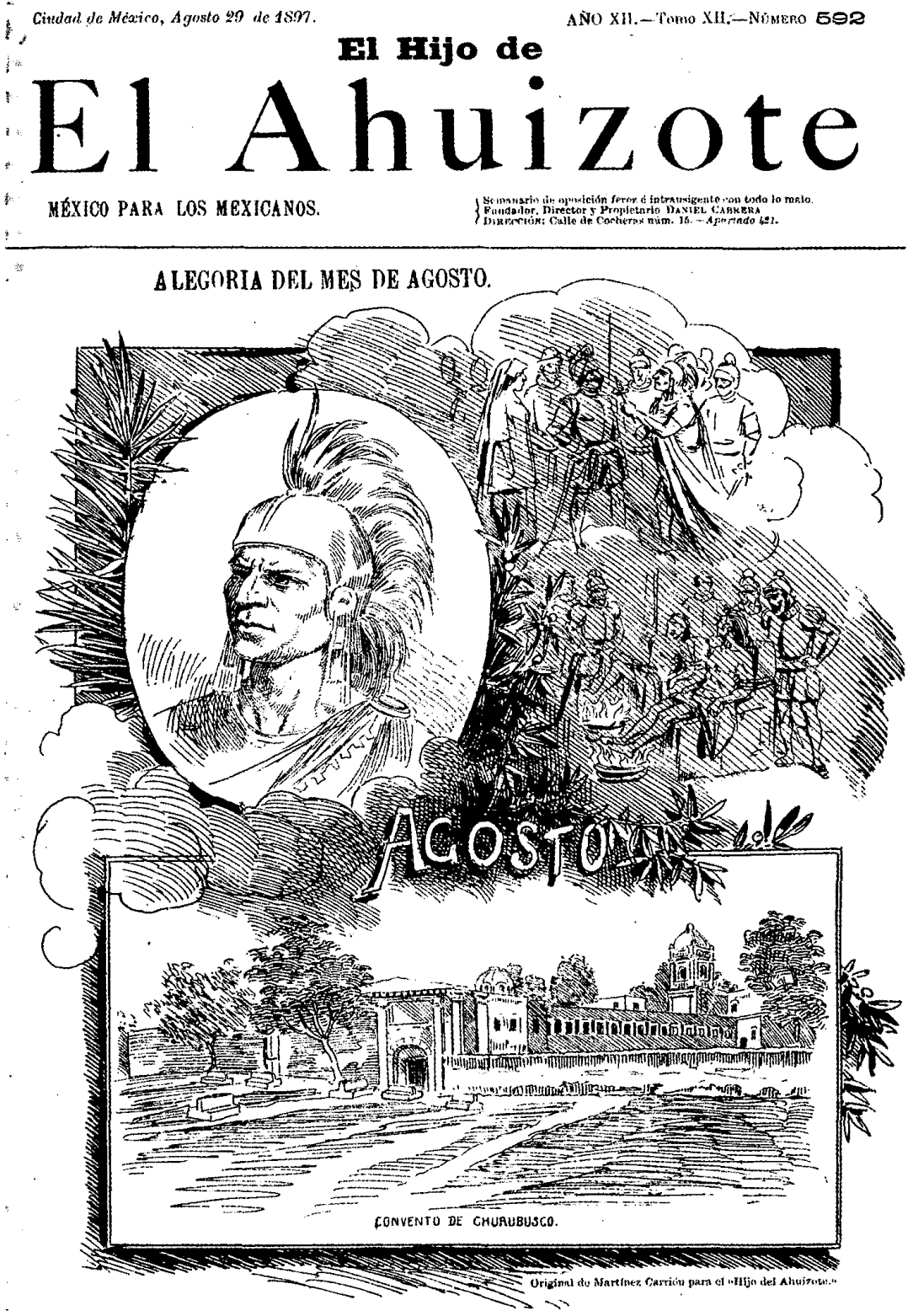


\section{Diana Guillén}

Socióloga que durante más de diez años ha trabajado el tema de Chiapas y ha escrito varios textos sobre los procesos políticos que en el largo y corto plazos han delineado la historia de la entidad. Desde 1984 es profesora-investigadora del Instituto Mora y también a partir de ese año imparte clases en la Facultad de Ciencias Políticas y Sociales de la UNAM. Actualmente es responsable de un proyecto financiado por CONACYT que se denomina ¿Todo en Chiapas es México?: Proyectos Políticos Nacionales y Rupturas Estatales, 1973-1993.

\section{Resumen}

La coyuntura que en 1994 lleva a la aparición de un movimiento armado en Chiapas involucra elementos de carácter estructural propios de la larga duración y otros más que se gestan en la esfera política dentro del corto plazo. El objetivo del artículo es rescatar esta segunda dimensión y analizar los mecanismos que entre 1973 y 1993 se utilizaron para ejercer ciertas funciones de gobierno, a partir del supuesto de que durante ese lapso los límites del aparato estatal para reproducir el orden quedaron en evidencia.

\section{Palabras clave:}

Política, instituciones, gobernabilidad, violencia, Chiapas.

\section{Abstract}

The situation that led to the emergence of the armed movement in Chiapas in 1994 involved certain long-term structural factors and other short-term ones that emerged within the political sphere. The aim of the article is to recover this second aspect and to analyze the mechanisms used between 1973 and 1993 to exercise certain government functions, on the basis of the assumption that the limited ability of the state apparatus to maintain order was revealed during this period.

Key words:

Politics, institutions, governance, violence, Chiapas.

Fecha de recepción: octubre de 2002

Fecha de aceptación: agosto de 2003 


\title{
Chiapas y el arte de gobernar: apuntes sobre una historia reciente, 1973-1993
}

\author{
Diana Guillén
}

L a gobernabilidad está lejos de representar un concepto abstracto y exclusivo de los análisis académicos; su ingreso de lleno en estos últimos se remonta a la década de los setenta, cuando se gestaron coyunturas que parecían retar la capacidad institucional para ejercer el poder. ${ }^{1}$ Sin embargo, las variables y procesos a los que alude han formado parte del escenario político desde tiempo atrás $\mathrm{y}$, se construyan o no instrumentos analíticos que den cuenta de ello, seguirán ocupando un lugar importante dentro de él.

De hecho, conforme las sociedades se vuelven más complejas, las desavenencias entre los ámbitos público y privado parecen profundizarse (sobre todo desde el punto de vista de amplios sectores marginados por modelos de desarrollo que tienden a polarizar el espectro social), y las posibilidades de gobernar efectiva y legítimamente se esfuman. ${ }^{2}$ El paradigma de p. 6.

1. Véase Arbós y Giner, Gobernabilidad, 1993 ,

${ }^{2}$ Si bien, como señala Antonio Camou, "quizá el principal acuerdo entre los autores que ban tratado el tema de la gobernabilidad con algún detalle es que no bay un acuerdo sobre su significado, el trasfondo que permite utilizarlo como herramienta conceptual gira alrededor de dos variables que hipotéticamente serían inherentes a la función de gobernar: la eficacia y la legitimidad". Véase Camou, Desafíos, 2001, pp. 10 y 16; Arbós y Giner, Gobernabilidad, 1993, p. 6. ciudadanos iguales sobre el que se construye la posibilidad de recurrir a la democracia como forma de gobierno parece cada día más lejano de una realidad en la que franjas importantes de la población subsisten en condiciones de pobreza extrema y sin acceso a formas de vida acordes con el desarrollo tecnológico-cultural propio de este fin de milenio.

A pesar de discursos oficiales y de alegres cuentas derivadas de cifras macroecónomicas, para el mexicano medio los niveles de bienestar se han reducido. Sectores urbanos paulatinamente pauperizados dan cuenta de ello, pero también las zonas rurales, donde el margen para empeorar parecía no existir, han resultado afectadas. Si se voltea la mirada hacia Chiapas, la historia de inequidades se remonta al pasado, pero en el presente se entronca con fuertes impulsos encaminados en la misma dirección y cuya esencia rebasa los límites de la entidad e incluso del país.

Las desigualdades estructurales que por siglos han impregnado el paisaje chiapaneco escapan a los objetivos y posibilidades de las reflexiones que a continuación se presentan, pero deben ser consideradas como marco de referencia a la hora de adentrarse por los laberintos construidos alrededor del intercambio político. Dentro de este último, el tema que 
hilvanará la exposición tiene que ver con los mecanismos utilizados durante las últimas tres décadas al ejercerse ciertas funciones de gobierno. Como veremos en seguida, se trata de un periodo en el que los límites del aparato estatal para reproducir el orden quedaron en evidencia y, conforme el escenario social se tornaba más conflictivo, el recurso de la fuerza directa reemplazó otro tipo de mediaciones.

\section{SOCIEDADES VEMOS, CIUDADANOS NO SABEMOS}

A partir de 1994 los temas relacionados con Chiapas saltaron a un primer plano. La aparición en la escena pública del Ejército Zapatista de Liberación Nacional (EZLN) obligó a replantear discursos oficiales empeñados en colocar a México como parte de un primer mundo, al que muchos mexicanos ni siquiera por foto podían acercarse; zonas enteras del país, entre ellas la que aquí nos ocupa, contradecían las imágenes vendidas en el exterior.

El lado oscuro de la tan ansiada modernidad quedó al descubierto y no fue necesario trasladarse para comprobar in situ la miseria de la gente, o aceptar por buenas las versiones que sobre la misma daban los opositores al régimen. Las cifras estadísticas incluidas en los resultados censales de 1990 se encargaban por sí solas de mostrar los bajos o nulos índices de bienestar existentes en la entidad (véanse cuadros 1 y 2).

En medio de tal panorama, uno se pregunta qué tipo de intercambios políticos podían existir. De entrada, el concepto de ciudadanía había perdido cuerpo y quedaba claro que el conjunto del enramado social dependía de hilos verticales más que horizontales. Se trata de un supuesto muy simple, que por obvio a veces se olvida; de allí que no esté de más insistir en la importancia de vincular el análisis de los métodos a los que se ha recurrido para llevar adelante la tarea de gobernar, con los procesos que le han impreso su perfil particular a los gobernados.

Tanto los límites como los alcances de cualquier forma de gobierno dependen del tipo de relaciones sociales en las que se enmarcan. Desde tal perspectiva, aun si formalmente se asumen los principios republicanos y democráticos, y se establece que "la soberanía reside esencial y originalmente en el pueblo, quien la ejerce por medio de los poderes públicos, que se instituyen para su beneficio", ${ }^{3}$ en Chiapas las entrañas de tal soberanía remiten a patrones oligárquicos que restringen, cuando no impiden, cualquier tipo de participación popular.

Las decisiones públicas se han mezclado tradicionalmente con los intereses de una elite poco interesada en superar usos y costumbres atávicos. El actuar de sus integrantes ha sido marcado a través de los siglos por la certeza de poseer una cierta superioridad respecto a quienes, también a través de los siglos, han actuado como sus subordinados. Los matices racistas de dicha concepción son innegables, pero más que juzgarlos en función de criterios ético-morales, interesa resaltarlos como ingrediente indispensable de las fórmulas políticas imperantes. ${ }^{4}$

$\mathrm{Si}$ se revisa la historia de la entidad, resulta evidente el divorcio entre amplias capas de la población y los poderes supuestamente instaurados para su benefi-

\footnotetext{
${ }^{3}$ Constitución, 1991, p. 1.

${ }^{4}$ Véase Gall, "Elementos", 1998, pp. 162-179.
} 
Cuadro 1

Chiapas Estados Unidos Mexicanos

Población analfabeta de quince

años y más

$30 \%$

$12.41 \%$

Población de seis a catorce años que

no sabe leer y escribir ${ }^{c}$

$26.6 \%$

$12.32 \%$

Distribución de servicios en la vivienda ${ }^{\mathrm{d}}$

Con agua entubada

$58.4 \%$

$41.2 \%$

$79.38 \%$

Con drenaje

$66.9 \%$

$63.62 \%$

Con energía eléctrica

$87: 51 \%$

Distribución de las viviendas particulares

según material predominante en techos ${ }^{e}$

$\begin{array}{lrc}\text { Lámina de cartón } & 9.6 \% & 9.7 \% \\ \text { Palma, tejamanil o madera } & 11.5 \% & 8.52 \% \\ \text { Lámina de asbesto o metálica } & 36.2 \% & 17.9 \% \\ \text { Teja } & 26.9 \% & 9.55 \% \\ \text { Losa de concreto, tabique o ladrillo } & 14.1 \% & 51.41 \% \\ \text { Otros materiales } & 1.3 \% & 2.34 \% \\ \text { No especificado } & 0.5 \% & 0.6 \%\end{array}$

Cuadro elaborado con base en datos absolutos extraídos del XI Censo, 1990.

"XI Censo, 1990, t. 1, cuadro 9, pp. 359-404.

${ }^{\mathrm{b}}$ Municipios con porcentaje más alto de analfabetismo en la población de quince años y más en Chiapas: Sitalá 71.1\%; Chamula 70.9\%; Mitontic 68.3\%; San Juan Cancuc 66.4\%; Zinacantán 63.3 por ciento.

' XI Censo, 1990, t. I, cuadro 8, pp. 318-356.

${ }^{d}$ Los municipios que en 1990 registran los más altos porcentajes en disponibilidad de servicios fueron: en electricidad, Tuxcla Gutiérrez con $96.8 \%$, Arriaga $90.2 \%$, y Alcalá $89.8 \%$; en agua entubada, Osumacinta 95.7\%, Tuxtla Gutiérrez $84.7 \%$, y Chicoasén $80.7 \%$; y en drenaje, Tuxtla Gutiérrez $85.4 \%$, Reforma $68.7 \%$ y Tapachula 67.7\%. XI Censo, 1990, t. Iv, cuadro 66, pp. 2557-2563.

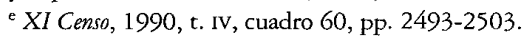

cio. La amalgama perfecta entre unos y otros no existe ni en sociedades menos polarizadas, pero en el caso de Chiapas, los puntos de intersección con ese espectro utópico han sido mínimos y por ello la supervivencia del régimen ha descansado sobre todo en un aparato estatal, cuyas ra- mas pierden su supuesta institucionalidad a la hora de ser empleadas y en canales informales que las suplen o refuerzan.

En abstracto, la tarea de gobernar supone aplicar la fórmula DEMANDAS DE LA SOCIEDAD + RESPUESTAS EFICIENTES Y LEGÍTIMAS DE LA 


\section{SECUENCIA}

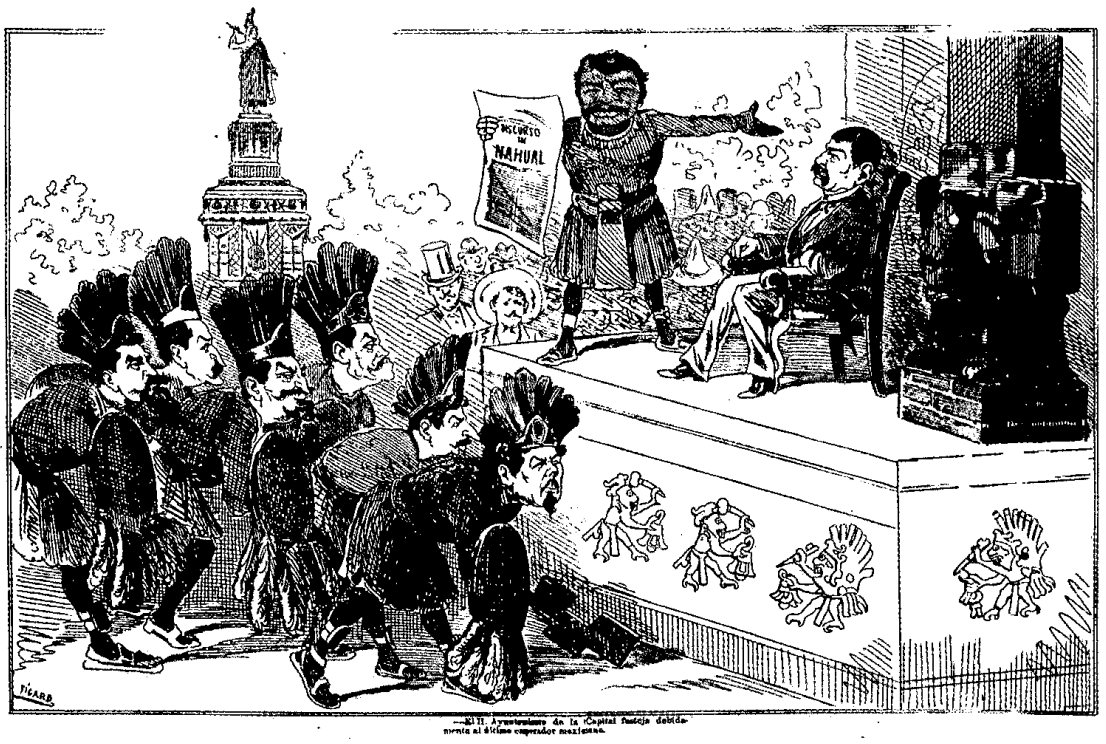


AUTORIDAD PÚBLICA = ACUERDOS. Nuevamente la vida cotidiana establece matices sobre un resultado en el que tanto los encuentros como los desencuentros entre ambas variables de la ecuación dependen de interacciones que se construyen momento a momento. Desde tal perspectiva es difícil hablar de gobernabilidad o ingobernabilidad absolutas, ${ }^{5} \mathrm{y}$ más bien tendría que pensarse en escenarios con mayor o menor índice de conflictividad resuelta.

Si bien ninguno de los dos extremos se llega a materializar, quizá el referente más cercano para las trayectorias continental (pienso en América Latina), nacional y estadual sea el segundo; sin caer en idealizaciones que, al relegar el carácter estructural de muchos de los enfrentamientos que se gestan en las sociedades modernas, acaban por justificar el mantenimiento de órdenes altamente excluyentes a través de la idea de gobernabilidad, ${ }^{6}$ me parece que ésta alude a un umbral de manejo democrático y racional de los asuntos públicos y que en tal sentido las cercanías y lejanías contrastables empíricamente constituyen indicadores importantes.

Siguiendo a Antonio Camou, entre los conceptos límite de gobernabilidad ideal (una respuesta adecuada para cada demanda y la consecuente ausencia o neutralización de conflictos) e ingobernabilidad (la virtual disolución de las relaciones de gobierno) se puede dibujar un espectro continuo de grados de gobernabilidad:

5 Véase Camou, Gobernabilidad, 1995, p. 25, y Desafíos, 2001, pp. 37-39.

- ${ }^{6}$ Reflexiones sugerentes y originales a propósito de este tema pueden verse en Stolowicz, "Gobernabilidad", 1997, pp. 187-213.
Cuadro 2. Población de seis a catorce años que no sabe leer y escribir en Chiapas, 1990

$\begin{array}{cc}\text { Edad } & \text { Porcentaje } \\ 6 & 75.7 \\ 7 & 37.8 \\ 8 & 27.5 \\ 9 & 19.3 \\ 10 & 17.3 \\ 11 & 15.7 \\ 12 & 15.2 \\ 13 & 12.3 \\ 14 & 12.7\end{array}$

Fuente: Datos absolutos extraídos del XI Censo, 1990, t. I, cuadro 8, pp. 318-356.

gobernabilidad normal (un equilibrio dinámico en el que las diferencias entre demandas y respuestas se refuncionalizan socialmente); déficit de gobernabilidad (un desequilibrio entre las demandas y las respuestas percibido como inaceptable por actores organizados); y crisis de gobernabilidad (una conjunción inesperada $y / o$ intolerable de desequilibrios entre demandas y respuestas). ${ }^{7}$

De retomar estas ideas para Chiapas, encontraremos requerimientos sociales básicos convertidos en focos de disputa capaces de tensar la relación sociedad-gobierno y atestiguaremos la emergencia de una crisis frente a la cual todavía no se encuentra el rumbo. Durante el periodo que me interesa analizar (1973-1993), movilizaciones de distinto tipo dieron cuenta de dicha situación y salieron a flote problemas que iban del ámbito estructural (como los relativos a la propiedad agra-

\footnotetext{
7 Véase Camou, Desafíos, 2001, pp. 38-39.
} 
ria) al de las preferencias religiosas, pasando por cuestiones laborales. En todos los casos se trataba de desavenencias generadas en la esfera de lo privado y, sin embargo, en las que la intervención gubernamental estaba lejos de restringirse al arbitraje.

A tales aristas de conflicto se sumaron las derivadas de impugnaciones y exigencias frente al aparato estatal; sin tratarse de un fenómeno generalizado que permitiese hablar de tendencias aplicables a toda la entidad, durante las décadas mencionadas se fueron gestando semillas de ciudadanización. Desde mi punto de vista, con todo y la escasa o nula respuesta que tuvieron la mayoría de los esfuerzos realizados en ese lapso para dejar constancia de viejos y nuevos descontentos, y para intentar revertir sus causas, canales de participación paralelos a la estructura oficial, abrieron espacios que, por la vía de los hechos, ampliaron el margen de acción de sectores tradicionalmente marginados.

Tal vez no se respetasen sus derechos, $o$, incluso, ni contasen con los requisitos mínimos para ser considerados ciudadanos en toda la extensión de la palabra, ${ }^{8}$ pero, de manera aislada y casi siempre inconexa, se incrementó el número de chiapanecos que cuestionaba abiertamente aspectos operativos del orden político y que exigía desde el mejoramiento de los servicios hasta la destitución de funcionarios.

Después de la efervescencia social hubo organizaciones independientes y oficiales que en muchos de los casos se encargaron de animar y encausar la insatisfacción de la gente; culparlas a ellas (sobre

\footnotetext{
${ }^{8}$ Para un análisis sugerente de lo que ha implicado en Chiapas construir espacios de ciudadanía véase Harvey, Rebelión, 2000.
}

todo a las primeras) por la creciente ola de reclamos y los métodos empleados para presentarlos, ha sido una de las tantas tácticas seguidas en los intentos por minimizar la pérdida de control sobre ciertos sectores y zonas de Chiapas. De allí que, sin negar la influencia de agentes externos en las diversas acciones a las que se recurrió para cuestionar el orden imperante, me parezca más útil resaltar el terreno fértil que encontraron. Finalmente su éxito como impugnadores del statu quo, sólo se explica a partir de la conjunción con una memoria colectiva en la que, a través de los siglos, abrevaron experiencias fallidas en cuanto a construir relaciones sociales más equitativas.

En este punto conviene recordar que la historia de Chiapas parece hilvanarse en torno a agravios y resistencias. ${ }^{9}$ Quienes han ocupado los últimos peldaños de la escala social han sido marginados prácticamente en todas las esferas y, al mismo tiempo, han retado de diversas maneras al orden que los sojuzga. Se trata de una relación construida a lo largo de los siglos y que consciente $o$ inconscientemente forma parte de los referentes identitarios de la población.

Ciertos recodos de esa memoria colectiva guardaban, pues, los recuerdos de las luchas dadas y de las que no se dieron. Difícilmente podría plantearse que existía una acumulación de fuerzas capaz de sustentar movimientos socialmente orgánicos o que la coyuntura iniciada en la década de los setenta era el resultado lineal de situaciones previas. Sin embargo, mi idea es que a lo largo del tiempo se había mantenido un intercambio societal basado en polarizaciones profundas y que, más allá

\footnotetext{
${ }^{9}$ Véase García de León, Reristencia, 1985.
} 
de las peculiaridades propias de cada momento y lugar, esta esencia compartida formaba parte del inconsciente (y algunas veces del consciente) de quienes participaban en él.

Los efectos de la desigualdad social tocaban por igual tanto a quienes se rebelaban como a quienes preferían asumir los costos de mantenerse dentro de los cánones establecidos. Esta esencia común en ciertos casos condujo a acciones contestatarias, en otros contribuyó a generar consignas ciudadanas, y en otros más permaneció latente. Desde tal perspectiva, el alma de las movilizaciones tendría que rastrearse en factores internos, en lugar de buscar demonios ajenos que, aprovechando el malestar local, lograron manipular a los involucrados.

En síntesis, una historia plagada de conflictos mal resueltos es la que brinda sustento a la efervescencia de las últimas décadas y la que, al mismo tiempo, permite acumular conocimientos en el terreno de las luchas sociales y políticas. Insistiría en que ninguno de los dos casos responde a procesos mecánicos; por el contrario, tanto los brotes de descontento como la aceptación de condiciones de vida poco favorables tuvieron que ver con los planos subjetivo e individual y objetivo y social. Las combinaciones de los ingredientes involucrados en cada plano produjeron coyunturas específicas, por eso, aunque las condiciones materiales fuesen las mismas, las respuestas ante estímulos sociales similares variaron entre grupos (e incluso entre individuos) que parecían compartir trayectorias.

A partir de este punto de vista, se entiende el abanico de organizaciones distribuidas en distintas zonas de la entidad; su éxito o fracaso dependía de condiciones locales, y aun cuando ocasionalmente unieron esfuerzos, por lo general se presentaban como proyectos con lógicas propias. Asimismo, se explica la convergencia de intereses distintos y a veces antagóni$c o s$, en bloques sociales cuyo principal cohesionador era el desafío al aparato estatal. Por último, también adquiere sentido la aparente inamovilidad de quienes aceptaron su situación sin protestar.

Mi hipótesis es que, en la década de los setenta, las bases del intercambio entre sociedad y aparato estatal ya mostraban signos de desgaste; entre otras cosas, los mecanismos para reproducir el orden perdían eficiencia y, a pesar de que los retos al mismo seguían lógicas focalizadas, tras ellos había un malestar que rebasaba los puntos geográficos en los que se manifestaba. ${ }^{10} \mathrm{La}$ atomización de las movilizaciones y la capacidad para mantener bajo control al conjunto de la entidad llevó a perder de vista las dimensiones de la crisis por la que se pasaba. Se confiaba en la eficiencia de los métodos con los que hasta ese momento se había asegurado la gobernabilidad, y se subvaluaba el potencial de una ciudadanía a la que sistemáticamente se había cortado cualquier posibilidad de asumirse como tal. ${ }^{11}$

\section{EL ARTE DE GOBERNAR}

Al tiempo que las exigencias sociales subían de tono, la respuesta gubernamental

${ }^{10}$ Un desarrollo más amplio del desgaste estructural que a mi juicio padecían las relaciones sociedadEstado en la entidad y de sus efectos en el ámbito de la política puede encontrarse en Guillén, Chiapas, 1998.

${ }^{11}$ Ibid. 
privilegió el corto plazo para enfrentarlas. A pesar de los cambios de estafeta entre distintas cabezas del ejecutivo estadual (de 1973 a 1993 hubo seis gobernadores), una misma línea marcó la toma de decisiones respecto a la solución de conflictos, $y$, sin tocar las cuestiones de fondo que los provocaban, buena parte de las veces se les desactivó por la vía de la fuerza.

El uso de esta última forma parte de las atribuciones de cualquier gobierno legalmente constituido; monopolizarla y ejercerla en aras del bien común evita la proliferación de la violencia. El problema en Chiapas era que la seguridad pública se confundía con la protección de intereses privados; si a ello agregamos la existencia de mecanismos de fuerza paralelos a las corporaciones dependientes del Estado, la ausencia de legitimidad en torno a las tácticas empleadas tomaba forma.

Durante el periodo que nos ocupa, la falta de alternativas institucionales para participar, e incluso para hacerse oír, favoreció formas de lucha que en algunos casos podían acogerse al derecho constitucional de todo mexicano para expresar sus ideas (manifestaciones, marchas, mítines y hasta plantones), pero que en otros más rebasaban los límites de la legalidad (bloqueos, toma de inmuebles e invasiones de predios). Cubiertos o no por la ley y con mayores o menores niveles de justicia, amparando sus demandas, quienes recurrían a las presiones citadas se convertían en factor de amenaza contra la reproducción del orden.

Cuando se involucraban instancias federales con funciones estratégicas para el conjunto del país - concretamente Petróleos Mexicanos (PEMEX) y/o la Confederación Federal de Electricidad (CFE)-, la reacción tenía que ser inmediata. En tales casos cabía la posibilidad de recurrir a la negociación, aun si dado el traslape de esferas de poder ello resultaba complicado. Un buen ejemplo en tal sentido tuvo lugar durante el gobierno de Juan Sabines, quien fue acusado de actitudes populistas que iban de la cooptación a la represión y conocido por tomar decisiones que más de una vez alteraron el equilibrio de fuerzas locales; dicho político intervino ante los campesinos de Reforma, Estación Juárez y Pichucalco que, en 1981, bloquearon los caminos de acceso a las instalaciones y equipos de PEMEX en la zona. ${ }^{12}$

Los inconformes exigían 1000 millones de pesos de indemnización ${ }^{13}$ y Sabines se comprometió a apoyarlos, ${ }^{14}$ aunque en estricto sentido el asunto escapaba de su jurisdicción. De hecho, tanto él como los presidentes municipales a los que correspondía intervenir eran fundamentalmente mediadores de un enfrentamiento derivado de políticas federales más que estaduales o municipales. El comité encargado de tramitar las reclamaciones reflejaba el carácter $b i$ y no multi polar de los actores involucrados en el problema: sólo PEMEX y los campesinos podían resolverlo, cuando el primero accediera a pagar lo solicitado y los segundos aceptaran el monto. ${ }^{15}$

${ }^{12}$ Véase César Espinoza, "Grupos armados tienen bloqueadas instalaciones de PeMEX en Chiapas", El Día, 19 de enero de 1981, p. 1.

${ }^{13}$ Véase César Espinoza, "Indemnización por mil millones piden a PeMEx los campesinos de Chiapas", El Día, 20 de enero de 1981, p. 2.

${ }^{14}$ Véase César Espinoza, "Arreglado el problema entre Pemex y campesinos chiapanecos", El Día, 20 de enero de 1981, p. 1.

${ }^{15}$ Véase César Espinoza, "Más de 10 mil campesinos reclaman pago a PEMEX", El Día, 21 de enero de 1981, p. 2. 


\section{al Iifo de}
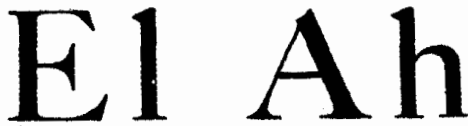

ul 1
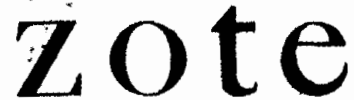

MEXICO PARA LOS MEXIOANOS.

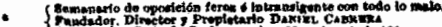

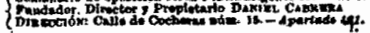

\section{Mister Bryan en Iísxico.}

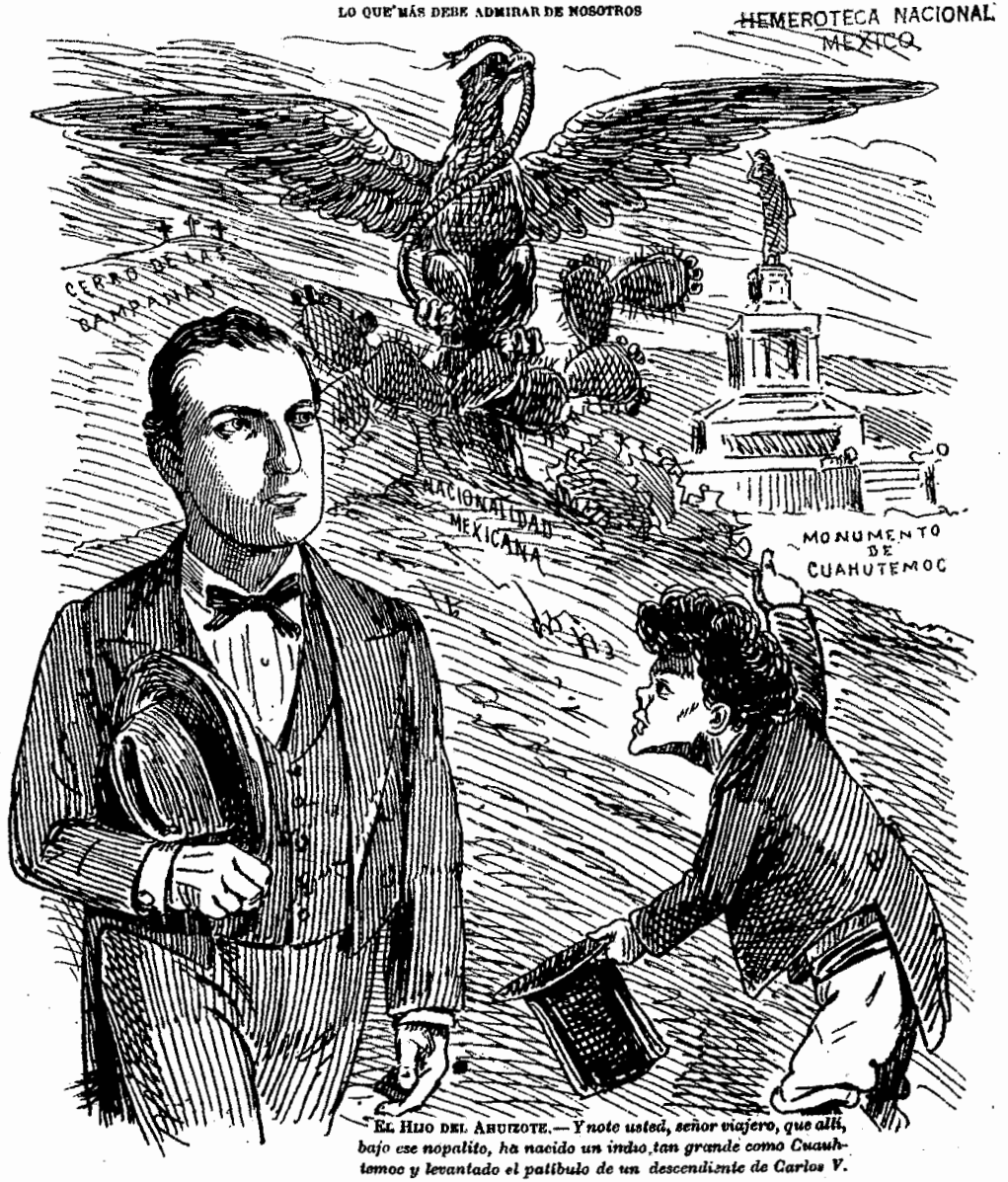


En este caso, la fuente original de conflicto rebasaba las dinámicas locales; se trataba de una contradicción irresoluble, en la medida en que las necesidades de hidrocarburo poco vinculadas al territorio del que se extraía generaban consecuencias no solicitadas, ni en general deseadas por los habitantes del lugar. Sin embargo, la posibilidad de cancelar las actividades petroleras, o bien, de restaurar en su justa dimensión el daño que ocasionaban, estaba fuera de toda agenda. ${ }^{16}$

Los saldos en términos de gobernabilidad eran obvios: había que lidiar con protestas que la administración chiapaneca podía paliar, pero no solucionar. Sólo año y medio después de los sucesos descritos, alrededor de 800 campesinos de la misma zona ocuparon los complejos petroquímicos de El Cactus y Tabasco, ${ }^{17}$ y posteriormente impidieron el paso a los trabajadores de PeMex. ${ }^{18}$ En 1985, una vez más el malestar afloró y en menos de un mes se pasó de soluciones aparentes ${ }^{19}$ a males recurrentes. ${ }^{20}$

16 "La industria petrolera es de utilidad puiblica prioritaria sobre cualquier aprovechamiento de la superficie y del subsuelo de los terrenos, incluso sobre la utilidad social de los ejidos o comunidades, establecen las enmiendas legales que en 1977 eliminaron cualquier duda sobre la preeminencia de PEMEX dentro de los territorios en los que hubiese la posibilidad de extraer petróleo." Véase Salazar y Whizar, "Participación", 1998, pp. 55-64.

${ }^{17}$ Véase Juan Ochoa, "Ocupan complejos petroquímicos ejidatarios de Reforma, Chiapas", Excélsior, 4 de julio de 1982, p. 31-A.

${ }^{18}$ Véase Porfirio Díaz López, "Demandan a PEMEX pague indemnizaciones", Excélsior, 14 de julio de 1982, p. 7-D.

19 Véase "Levantan el bloqueo a pozos de PEMEX", Excélsior, 10 de febrero de 1985, p. 8-D.

${ }^{20}$ Véase "Piden campesinos de El Blanquillo, en Chiapas, que PEMEX, los indemnice", Excélsior, 24 de febrero de 1985 , p. 2.
Otra de las instituciones federales que tuvo incidencia sobre la vida local fue la CFE. Al utilizar terrenos que tradicionalmente se habían dedicado a la agricultura, provocó reacomodos poblacionales importantes. Miles de hectáreas cultivables quedaron bajo el agua y otras tantas se inutilizaron de manera indirecta a partir de la década de los setenta, situación que además de incrementar la presión sobre la propiedad rural convirtió a muchos chiapanecos en habitantes irregulares de zonas urbanas. ${ }^{21}$ Una vez más se cobraban en el plano local costos de políticas diseñadas fuera de la entidad y sin importar sus efectos para la misma.

De hecho, la construcción de hidroeléctricas formaba parte de un vasto programa que, en el sexenio de Luis Echeverría, pretendía utilizar el potencial de los ríos Usumacinta y Grijalva para generar más de la mitad de la energía que el desarrollo industrial del país requería (se hablaba de 7000000 de kilovatios). El proyecto estaba pensado a un plazo de diez años, pero se prolongó por más tiempo y, además de las presas Malpaso, Chicoasén, La Angostura, Itzantún, Peñitas, dejó atrás un fuerte descontento social entre los afectados. ${ }^{22}$

También aquí una de las sendas que siguieron las protestas fue tomar instalaciones y bloquear caminos. En 1985, por ejemplo, cerca de 300 campesinos de los municipios de Huitiupán y Simojovel optaron por dicha vía, ante la negativa de la CFE de restituirles tierras para reacomo-

${ }^{21}$ Véase Rodríguez, "Torno", 1989, p. 142.

${ }^{22}$ Véase Mendoza, "Intervención", 1995, pp. 136-137. 
dar los ejidos afectados por Itzantún, ${ }^{23}$ no obstante que cuatro años antes la Comisión se había comprometido a indemnizar a los 15000 afectados y a reubicarlos. ${ }^{24}$ La lucha de quienes perdieron su principal recurso económico frente a la instancia federal se empalmaba, sin embargo, con las ya de por sí crecientes demandas agrarias que caracterizaban el escenario chiapaneco, de allí que la interlocución con la CFE ocupase un segundo plano y las demandas y estrategias de los movilizados se sumasen a las del resto de campesinos que venían peleando asignaciones y/o reconocimiento de tierras.

En otras palabras, la presencia de un organismo ajeno al entorno estadual coadyuvó a agudizar conflictos estructurales que, en los hechos, constituían el principal reto para llevar a buen término la tarea de gobernar. Al iniciar la década de los ochenta, se mencionaban 400 invasiones de tierra, 7000 conflictos por parcelas, 350 entre ejidos y comunidades, 70000 campesinos que solicitaban tierras abiertamente y cerca de 100000 que las poseían pero de manera pulverizada. ${ }^{25}$

En 1994, la táctica que durante las dos décadas previas había permitido a grupos de distinta filiación ideológica y/o partidaria hacerse de espacios rurales en disputa llegó a su clímax. Las invasiones alcanzaron importantes magnitudes y además dejaron de concentrarse prioritariamente en algunos municipios de las

${ }^{23}$ Véase Amet Flores Meneses, "Ejidatarios de Huitiupán y Simojovel tomaron las instalaciones de la CFE", El Día, 22 de marzo de 1985.

${ }^{24}$ Rodolfo López Sol, "La CFE nunca nos indemnizó, acusan campesinos de Chiapas", Excélsior, 22 de marzo de 1985.

${ }^{25}$ Véase Rodríguez, "Torno", 1989, p. 141. regiones Centro, Selva y Norte (sobre todo Simojovel, Bochil, Ocosingo y Venustiano Carranza) para extenderse al resto del territorio. ${ }^{26}$

Se resalta el hecho aunque escape al periodo que aquí interesa, porque parecería que las semillas de ingobernabilidad vinculadas con las tomas de tierra mostraron todo su potencial alrededor de dicha coyuntura. A un año de que el EZLN se hiciera público, la ausencia de un Estado de derecho se denunciaba repetidamente; si bien no existe información precisa sobre el número de predios y la superficie invadidos, los datos disponibles son ilustrativos: de acuerdo con el líder de los ganaderos, fuera de la zona de conflicto había 565 predios invadidos, mientras que el secretario de Desarrollo Agrario de la entidad hablaba de 670 invasiones denunciadas ante la instancia judicial; las agencias ministeriales reportaban más de 1000 , y el titular del Programa de Bienestar Social y Desarrollo Sustentable (Dante Delgado) reconocía más de 2000 dentro y fuera de la zona de conflicto. ${ }^{27}$

Las invasiones eran en sí mismas subversivas, pero hasta ese momento se había disimulado su grado de peligrosidad porque, sin importar los costos en el mediano y largo plazos, siempre quedaba el recurso de enfrentarlas por la fuerza. Los ejemplos que ilustran las acciones estatales en contra de ellas se multiplican a lo largo de los años setenta, ochenta e inicios de los noventa. Guardias blancas, propietarios, ejército y corporaciones policiacas combinaron esfuerzos para mantener bajo control la situación y, más de una vez, los

\footnotetext{
${ }^{26}$ Véase Villafuerte et al., Tierra, 1999, pp. 131133.

${ }^{27}$ lbid., p. 132.
} 
abusos de los que fueron víctimas los invasores quedaron reseñados en la prensa chiapaneca e incluso en la nacional. ${ }^{28}$

Mi idea es que los límites inherentes a dicha forma de enfrentar el problema van más allá de una redistribución e incremento de los conflictos alrededor de la propiedad agraria; el que después de la aparición del EZIN se remarcase su poca legitimidad y eficiencia no implica que con anterioridad sí cubriese ambos requisitos. Para bien o para mal, el modelo de apropiación directa de la tierra formaba parte de una cultura con escaso respeto por la legalidad; si rastreamos sus orígenes, quizá debamos remontarnos a la etapa posrevolucionaria, cuando (bajo los gobiernos estadual de Efraín Gutiérrez y nacional de Lázaro Cárdenas), Erasto Urbina fue nombrado director del Departamento de Protección Indígena (DPI).

A las pocas semanas de haber asumido el cargo, Urbina y agentes montados del DPI invadieron la primera de las muchas fincas que expropiarían durante los dos años y medio siguientes, desconfiando de una reforma agraria demasiado lenta, en el mejor de los casos, e inoperante para la realidad chiapaneca en el peor de ellos. ${ }^{29} \mathrm{El}$ testimonio de uno de los propietarios afectados resulta ilustrativo de los métodos empleados:

El 13 de febrero de 1937, el señor Erasto Urbina [...] llegó a mi rancho San Antonio Las Rosas [...] con un grupo de individuos armados, y sin tramitación legal, ni pedimento alguno de tierras, estando mi men-

${ }^{28}$ Para un seguimiento más minucioso de este punto véase Guillén, "Chiapas", 2003.

${ }^{29}$ Véase Rus, "Comunidad", 1995, p. 259. cionado rancho ocupado con ganado vacuno y caballar, lo entregó en unos cuantos minutos a un grupo de chamulas, so pretexto de ser terrenos ociosos. ${ }^{30}$

La regularización vendría después; en principio se pugnaba por restituir, dotar o ampliar los fundos indígenas, pero, de no ser posible, se propiciaba la compraventa del área en disputa. Se trataba de una política de hechos consumados, tolerada por las esferas estadual y federal del poder. Lejos de existir mediaciones gubernamentales apoyadas en canales institucionales, se favorecía el enfrentamiento entre bandos particulares que, más allá del provecho o perjuicio obtenido en la inmediatez, a largo plazo generaron desconfianzas y resentimientos hacia las administraciones en turno.

Conforme las invasiones pasaban a ser parte consuetudinaria del paisaje chiapaneco, los retos a la gobernabilidad se potenciaban. Aquí conviene recordar que a pesar de las tendencias a favor del crecimiento urbano, ${ }^{31}$ el perfil de la entidad seguía siendo eminentemente agrario y la relación con la tierra representaba una piedra angular dentro de la estructura de poder y la cultura política locales.

Tierra y gente formaban un imbricado tejido: como valor agregado de la primera se contabilizaba la capacidad de control que se tuviese sobre aquellos que la habitaban y alrededor de dicha simbiosis se

${ }^{30} \mathrm{Ibid}$., pp. 259-260.

${ }^{31}$ De acuerdo con el censo de 1990, 1913754 habitantes eran considerados como población rural y 1296742 como urbana, pero esta última había aumentado en mayor proporción que la primera. Véase Agenda, 1992, pp. 164-171. 
construía un intercambio societal de corte servil, patrimonialista y clientelar. Dentro de escenarios que recordaban tiempos del porfiriato supuestamente superados, ${ }^{32}$ cuotas importantes de poder iban aparejadas a una propiedad agraria cuyas pugnas estaban lejos de constituir simples disputas de tipo económico.

Los patrones de socialización tradicionales, en los que descansaba ese mundo con aroma a campo, mostraban, sin embargo, signos de resquebrajamiento; cada vez más se requería utilizar las fuerzas pública y privada para reproducir el orden, y el espacio para satisfacer las demandas de la población se volvía sumamente estrecho. En este sentido, ya antes de que el EZIN apareciese en escena, focos rojos presagiaban altos niveles de tensión entre las esferas social y estatal.

Para ejemplificar los desencuentros entre una y otra esfera, 1985 se vuelve un año paradigmático. En ese momento se encontraba a cargo del ejecutivo estadual un militar de carrera (el general Absalón Castellanos), cuyo nombramiento difícilmente puede calificarse como hecho fortuito. ${ }^{33}$ Sólo quienes intervinieron directamente en su designación conocen los pesos y contrapesos que inclinaron la ba-

\footnotetext{
${ }^{32}$ Mucho se ha insistido sobre tales continuidades, pero un botón de muestra que me parece ilustrativo es el comentario de un chiapaneco que, ya rebasado el primer cuarto del siglo $\mathrm{xx}$, acompañaba los fines de semana a su tía para alquilar sus indios a la plaza de Comitán; allí, las personas interesadas en que les realizasen faenas domésticas o de otro tipo pagaban a la señora una suma y se llevaban por un tiempo al trabajador. Entrevista a ex funcionario chiapaneco realizada en la ciudad de México, julio de 1990.

${ }^{33}$ Véase Cruz, Absalón Castellanos, 1982.
}

lanza en su favor; pero el contexto en el que llegó y las acciones emprendidas durante su sexenio permiten suponer que se intentaba endurecer la mano para apuntalar estructuras de poder que presentaban serios problemas para refuncionalizarse.

Las expectativas de las cúpulas políticas se quedaron en eso y, a poco más de dos años de haber asumido el mando, las muestras de inestabilidad se incrementaron. En marzo el presidente Miguel de la Madrid no pudo entrar a Tuxtla porque los maestros estaduales y federales habían tomado el primer cuadro de la ciudad, al tiempo que los estudiantes ocuparon la universidad. Días antes, trabajadores de la Federación de Sindicatos de Trabajadores al Servicio del Estado (FSTSE) se habían apoderado de la delegación del Instituto de Seguridad Social al Servicio de los Trabajadores del Estado (ISSSTE); la Facultad de Derecho había sido ocupada; miembros de la Sociedad de Alumnos habían tomado la rectoría de la Universidad Autónoma de Chiapas (UNACh); el magisterio había realizado concentraciones; y campesinos pertenecientes a la Organización Campesina Emiliano Zapata (OCEZ) habían organizado un plantón en la plaza cívica. ${ }^{34}$ Un mes después, mientras Castellanos negaba que hubiesen problemas, se desató un paro de transportistas que dejó semiparalizada a la ciudad, al tiempo que un grupo de campesinos solicitaba audiencia a las puertas del palacio de gobierno. ${ }^{35}$

${ }^{34}$ Véase José Luis Mejías, "Los intocables", Excélsior, 19 de marzo de 1985.

${ }^{35}$ Véase J. Jaime Hernández, "Chiapas, suma de conflictos, y el gobernador dice: no hay problemas", Excélsior, 11 de abril de 1985. 


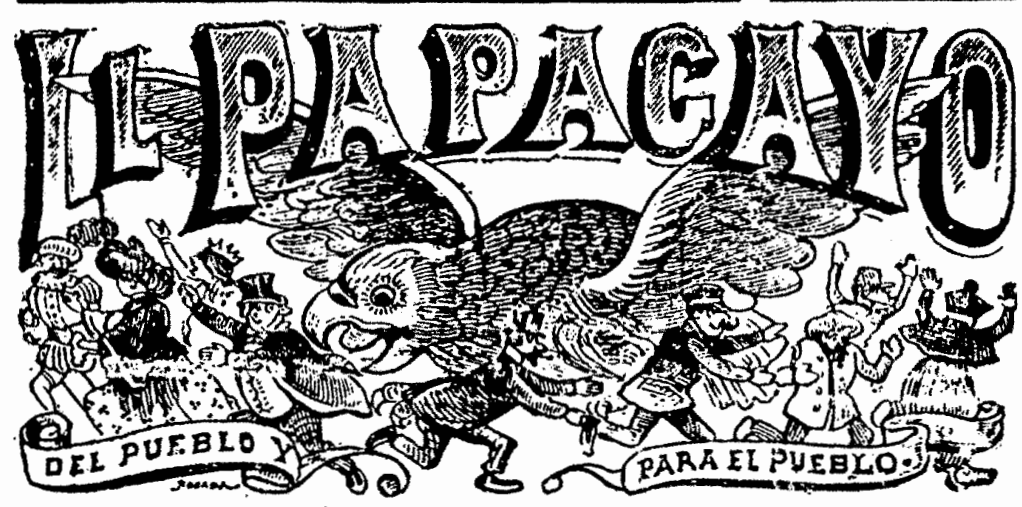

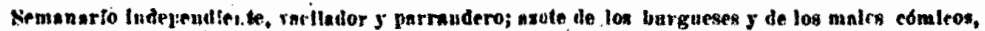
defensor tecondlcional conclapurive de In clase obrera.

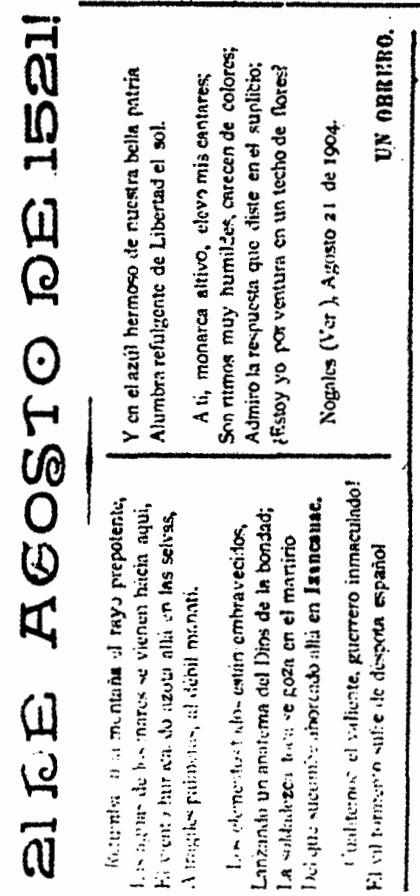
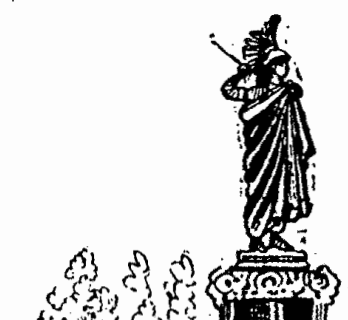
$\operatorname{lin}_{3}+3$

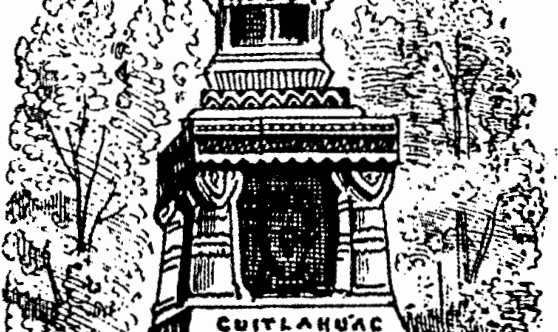
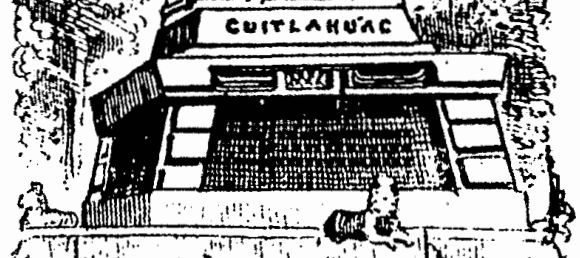
En julio, el centro de Tuxtla fue bloqueado por 700 personas, entre las que se encontraban indígenas expulsados de los Altos, miembros de la Coordinadora de Luchas Populares Emiliano Zapata e integrantes de la sección 7 del Sindicato $\mathrm{Na}$ cional de Trabajadores de la Educación (SNTE). Sus demandas abarcaban desde el regreso de los expulsados hasta la regularización de las colonias populares, pasando por el pago que se adeudaba a los caficultores. ${ }^{36}$

Cuando días después la Central Independiente de Obreros Agrícolas y Campesinos (CIOAC) organizó una marcha a la capital del estado, el gobierno decidió evitar los oficios mediadores de la organización (ante la negativa de los líderes para establecer el diálogo) y tratar directamente con los campesinos. De acuerdo con el diagnóstico que hiciera el subsecretario general de gobierno, la mayoría de los problemas planteados escapaban al ámbito estadual e involucraba tanto instituciones y organismos federales (Secretaría de Agricultura y Recursos Hidráulicos [SARH], la Compañía Nacional de Subsistencias Populares [CoNASUPO], Instituto Nacional Indigenista [INI], Instituto Mexicano del Café, Secretaría de la Reforma Agraria [sRA]), como instancias semioficiales y/o privadas (Banco de Crédito Rural del Istmo, Aseguradora Nacional Agrícola y Ganadera). En cuanto a las denuncias por la existencia de presos políticos y órdenes de aprehensión contra campesinos, se aseguró que el gobernador Âbsalón Castellanos había ordenado una investiga-

${ }^{36}$ Véase Pedro Arriaga, "700 paristas bloquearon el centro de Tuxtla Gutiérrez", El Universal, 17 de julio de 1985 . ción, pero de antemano se establecía que "quienes se encuentran en reclusorios de la entidad purgan condenas por haber incurrido en la comisión de delitos del orden común".37

A pesar de lo que el discurso afirmaba, en el acuerdo que finalmente se firmó quedaba incluida la liberación de cuatro presos políticos y el desistimiento de dos órdenes de aprehensión; además de que se establecía el compromiso de analizar once problemas agrarios y de otorgar créditos a 21 comunidades de los municipios de Comitán, Simojovel y Villa las Rosas. ${ }^{38}$

Agosto fue recibido con movilizaciones similares, ${ }^{39}$ y en octubre la disposición al diálogo se acabó: en un nuevo plantón cientos de campesinos exigían el cese a la represión y denunciaban a los caciques que aprovechaban su alianza con el gobierno. Mientras una comisión de los primeros dialogaba con representantes del último, la policía estadual dispersó a los inconformes a tiros y con gases lacrimógenos. La violencia alcanzó a quienes no participaban en el acto, y además de los 28 campesinos que resultaron heridos, el alcalde priista de Pueblo Nuevo, que observaba desde el balcón del edificio del Partido Revolucionario Institucional, fue seriamente lesionado. ${ }^{40}$ Algunos miembros del Partido Acción Nacional que es-

\footnotetext{
37 Véase "Comisión del gobierno de Chiapas para dialogar con marchistas de la CIOAC", El Día, 22 de julio de 1985.

38 Véase "Chiapas: se levantó el plantón frente a Palacio", El Dia, 27 de julio de 1985.

39 Véase "Turbulencia en Chiapas ante oídos sordos del gobierno", El Universal, 30 de julio de 1985.

${ }^{40}$ Véase Armando Sepúlveda y Leticia Hernán$\mathrm{dez}$, "Crece en el agro el repudio al gobernador Castellanos", Excélsior, 12 de octubre de 1985.
} 
taban en el parque fueron "brutalmente heridos por los policías, a pesar de que nos identificamos". 41

El nivel de conflictividad y la incapacidad del gobierno para controlarla llevaron a solicitar ante el Congreso de la Unión la desaparición de poderes. El informe de Eduardo Robledo, diputado federal en ese entonces, reconocía la inestabilidad política y social que privaba en Chiapas (caracterizada por la agudización del bandolerismo, la persecución ilegal, la permanencia de injusticias lacerantes y hasta el asesinato) y agregaba la necesidad de tomar medidas que permitieran el regreso al orden, la legalidad y la seguridad ciudadana. ${ }^{42}$

A pesar de las pruebas contundentes en sentido contrario, el plano discursivo reflejaba una negación de que la sociedad hubiese rebasado las ofertas institucionales para mediar sus vínculos con el aparato estatal. De acuerdo con las declaraciones oficiales, "todo estaba en calma". ${ }^{43}$

Además de las muestras elegidas para ilustrar los problemas que en 1985 enfrentaba el gobierno a la hora de ejercer sus funciones reproductoras del orden y de los otros ejemplos hasta aquí utilizados

${ }^{41}$ Véase "La situación en Chiapas, virtual estado de sitio: tres partidos", Uno más Uno, 26 de julio de 1985.

${ }^{42}$ Véase "Violencia chiapaneca", El Universal, 17 de octubre de 1985; Correa, "Gobernador", 1985, pp. 29-30; "Se multiplican", 1986, pp. 22-24.

${ }^{43}$ Véase "Será difícil que los partidos de oposición logren desestabilizar la paz de chiapanecos. No han mellado los programas gubernamentales", $E l$ Día, 15 de octubre de 1985; Guerra Pérez, "En Chiapas impera el mandato de la ley", El Día, 7 de noviembre de 1987; y Guerra Pérez, "La justicia en Chiapas da tranquilidad y seguridad al pueblo", $E l$ Universal, 7 de noviembre de 1987. con el mismo propósito, podrían citarse múltiples hechos históricos que, distribuidos en el lapso estudiado, cumplirían fines similares. Sin embargo, para evitar que el cúmulo de datos oculte las grandes tendencias, se retomaron, a partir de un orden que facilita su análisis, sólo algunos casos más que complementan lo expuesto. $^{44}$

Las acciones sociales que he considerado como retos en la tarea de gobernar quedaron agrupadas en tres categorías: a) las que estuvieron vinculadas con una apropiación de espacios públicos y privados (aquí incluyo desde las invasiones hasta las tomas de edificios urbanos, pasando por los bloqueos a las vías de tránsito y los plantones); b) las que iban asociadas a alguna forma de mostrar públicamente el descontento (aquí incluyo a las manifestaciones, marchas y mítines); ${ }^{45} c$ ) las que genéricamente formarían parte de la llamada seguridad pública (aquí incluyo procesos delictivos del orden común tales como robo, asesinato y secuestros).

${ }^{44}$ Las principales fuentes a las que se recurrió para elaborar esta parte fueron hemerográficas; si bien se tuvo acceso tanto a periódicos locales como a nacionales, se privilegió a los segundos porque el simple hecho de haber alcanzado ese plano (nacional) constituye un indicador sobre los alcances del conflicto o acción reseñados. Ahora bien, incluso a partir de esa primera selección, la cantidad de noticias era tan grande que se eligieron exclusivamente los más representativos y se dejaron fuera dos cuestiones también vinculadas con el ejercicio de gobierno (los conflictos religiosos y las disputas político-electorales), ya que ambas ofrecen material para elaborar trabajos específicos.

${ }^{45}$ Las huelgas no quedaron incluidas en ninguno de los dos rubros, porque si bien alrededor de ellas pueden generarse algunos de los procesos propios de ambas categorías (la lucha magisterial brinda buenos 
Respecto a la apropiación de espacios públicos y privados, se ha hablado de las invasiones rurales y de los bloqueos a instalaciones de algunos organismos de carácter federal, cuya presencia en la entidad alteró los equilibrios locales. Otras más de las ocupaciones realizadas tuvieron como escenario oficinas de gobierno (centralizadas y descentralizadas): las de la Secretaría de Educación Pública (SEP) ${ }^{46}$ las de recaudación de la Secretaría de Hacienda y Crédito Público (SHyCP), ${ }^{47}$ las del INI, ${ }^{48}$

ejemplos en este sentido), constituyen un canal de participación institucional que, en términos generales, no representaban amenazas importantes para la gobernabilidad.

46 Véase Porfirio Díaz López, "Sin solución el problema de los maestros en Chiapas", Excélsior, 28 de octubre de 1979, p. 7-D; Porfirio Díaz López, "Alumnos y maestros de la ESM toman las oficinas de la SEP en Chiapas", Excélsior, 28 de octubre de 1979, pp. 5-A y 12; César Espinoza, "Maestros sin pago, por la toma de las oficinas de la SEP", El Día, 28 de febrero de 1981, p. 3; José Rosemberg Ovilla, "3 000 normalistas de Chiapas tomaron instalaciones de la SEP, piden un presupuesto de 112 millones", El Universal, 4 de agosto de 1983, p. 19; "Ocupan la delegación de la SEP en 'Tuxtla Gutiérrez", El Universal, 5 de agosto de 1983, p. 23; Leticia Hernández, "Tomaron la Secretaría de Educación en Chiapas", Excélsior, 4 de septiembre de 1984, p. 32-A.

${ }^{47}$ Véase Leticia Hernández, "Se unen al paro de la CNTE en Tuxtla 30 mil maestros", Excélsior, 19 de marzo de 1989, pp. 1 y 3; Manuel Kinto, "Profesores toman en Tapachula las oficinas de recaudación de Hacienda", El Día, 16 de diciembre de 1988, p. 9.

${ }^{48}$ Véase Amet Flores Meneses, "Ocuparon instalaciones del INI en Chiapas campesinos tzotziles", $E l$ Día, 6 de julio de 1983, p. 6; Amet Flores Meneses, "Insisten indígenas en que Salomón Nahamad resuelva los problemas", El Día, 7 de julio de 1983, p. 6; César Barrientos, "Aumento a los productos de 5000 indígenas o no salen del INI", Excélsior, 13 de julio de 1983, p. 5-D; José Rosemberg Ovilla, "Devuelven indígenas chiapanecos las oficinas del las de la CONASUPO, ${ }^{49}$ las de BANRURAL, ${ }^{50}$ las de Tabacos Mexicanos (TABAMEX), ${ }^{51}$ las de la UACh, ${ }^{52}$ y también las del

INI en los Altos", El Universal, 16 de julio de 1983, p. 19; Heliodoro Cárdenas Garza, "Exigen tojolabales cese a la corrupción en el agro", El Día, 14 de junio de 1984, p. 6; Leticia Hernández, "Perjudica el papeleo a 118 de las comunidades indígenas tojolabales", Excélsior, 15 de junio de 1984, p. 7-D; Leticia Hernández, "Decenas de indígenas tojolabales tomaron las oficinas del INI", Excélsior, 10 de junio de 1987, p. 11-D.

${ }^{49}$ Véase "Ocupan bodegas para presionar a CONASUPO", El Día, 16 de enero de 1986, p. 8; "Agricultores de Chiapas firmes: mejor pago o no devuelven las bodegas", Excélsior, 18 de enero de 1986, p. 1; Leticia Hernández, "Toman campesinos 90 bodegas de CONASUPO en Villa Flores, Chiapas", Exiélsior, 28 de enero de 1986, p. 2 en los estados; "Se cumplen 30 días de la toma de bodegas a Conasupo en Chiapas", Excélsior, 23 de frebrero de 1986, p. 2 en los estados; Heliodoro Cárdenas, "Manos ajenas a verdaderos campesinos en la toma de bodegas $\mathrm{CO}-$ NAsupo en Chiapas", El Día, 4 de abril de 1986, p. 6; César Espinoza, "Campesinos de la Frailesca devolvieron las bodegas de CONASUPO", El Día, 14 de junio de 1986, p. 7.

${ }^{50}$ César Barrientos, "Ocupan cafeticultores de Chiapas la sucursal del Banco Rural del Istmo", Excélsior, 7 de mayo de 1983, p. 23-A.

${ }^{31}$ Rodolfo López Sol, "Devuelven plantaciones de Taвamex en Chiapas", Excélsior, 11 de marzo de 1984.

${ }^{52}$ Véase José Rosemberg Ovilla, "Toman estudiantes las instalaciones de rectoría de la UACh", $E l$ Universal, 30 de septiembre de 1983, p. 25; José Rosemberg Ovilla, "Toman instalaciones de la UACh, piden el cese del rector", El Universal, 28 de noviembre de 1984, p. 23; Amet Flores Meneses, "Continúa el conflicto en la UNACh; nadie depone actitudes", $E l$ Dia, 19 de febrero de 1985, p. 6; "Continúa el conflicto de la UNACh", Excélsior, 15 de febrero de 1.985, p. 4; "Lleva 20 días tomada la rectoría de la UACh, no se vislumbra solución", Excélsior, 6 de marzo de 1985, p. 3; "Un mes de ocupada la rectoría de la UAch", 
ISSSTE; ${ }^{53}$ aunque las dos últimas se incluyeron en el recuento de 1985, conviene volverlas a considerar desde el punto de vista temático más que cronológico, sobre todo en el caso de la UACh, donde se trató de un problema recurrente.

Las tomas incluyeron también ayuntamientos, a los que se les demandaba desde servicios hasta cuestiones de tipo electoral; ${ }^{54}$ empresas privadas contra las que

Excélsior, 17 de marzo de 1985, p. 4; "Entregan la rectoría alumnos y catedráticos de la UNAM", Excélsior, 23 de noviembre de 1985, p. 2 en los estados; Leticia Hernández, "La destitución del rector García Sánchez demandan los universitarios chiapanecos", Excélsior, 15 de enero de 1987, p. 10-A; "Fracasan las pláticas entre los alumnos de la UNACh y el rector", Excélsior, 17 de enero de 1987, p. 2 en los estados; Leticia Hernández, "Irrumpe la policía en la UNACh, heridos al desalojar alumnos", Excélsior, 18 de enero de 1987, p. 3 en los estados.

${ }^{53}$ Véase "Toman instalaciones del Issste Chiapas", Excélsior, 13 de febrero de 1985, p. 2.

${ }^{54}$ Véase Porfirio Díaz López, "Piden destituir al alcalde de La Concordia y toman la presidencia", Excélsior, 21 de octubre de 1983, p. 6-D; Humberto Aranda, "Frentes políticos. Ocupan alcaldías en Chiapas", Excélsior, 24 de octubre de 1983, p. 22-A; César Barrientos, "Se apoderaron priistas de la presidencia municipal de Socoltenango", Excélsior, 11 de diciembre de 1983, pp. 4-A y 6; Pedro Arriaga, "Continúan los campesinos de Pantepec, Chiapas, apoderados de la presidencia", El Universal, 11 de julio de 1985, p. 19; Leticia Hernández, "Ocuparon 300 habitantes de Chilón la presidencia municipal", Excélsior, $10 \mathrm{de}$ septiembre de 1985, p. 37-A; Alfredo Córdova, "Disparó la policía sobre burócratas; desalojan un ayuntamiento", Excélsior, 1 de febrero de 1986, p. 2 en los estados; Leonel D. López, "Toman indígenas el palacio de Jitotol, piden al alcalde cuentas sobre 80 millones de pesos", El Universal, 29 de abril de 1987, p. 27; Leonel D. López, "Tomarán una alcaldía en Chiapas", El Universal, 3 de junio de 1987, p. 22; Leticia Hernández, "Toman la alcaldía campesina de existían requerimientos económicos; 55 y locales pertenecientes a agrupaciones corporativas como la Unión Estatal de Productores de Café, ${ }^{56}$ la Asociación Nacional Agrícola y Ganadera (ANACSA), ${ }^{57}$ el Sindicato de Trabajadores del Gobierno del Estado ${ }^{58}$ y el SNTE. ${ }^{59}$ Otro tipo de apropiaciones fueron los medios de trans-

la independencia", Excélsior, 6 de diciembre de 1987, p. 2; Leticia Hernández, "Atacan partidarios del PST a policías que custodiaban la alcaldía de Simojovel, Chiapas", Excélsior, 9 de diciembre de 1987, p. 44-A; César Espinoza, "Toman campesinos las alcaldías de Amatán y Solosuchiapa, en Chiapas", El Día, 24 de diciembre de 1987, p. 7; César Espinoza, "Chiapas, mosaico de grandes diferencias", El Día, 4 de febrero de 1988, p. 7; "Frentes políticos. Ocupan alcaldía de Chiapas", Excélsior, 28 de diciembre de 1988, p. 26-A; Leticia Hernández, "Formal demanda en Tapalapa, Chiapas, contra 27 priistas", Excélsior, 29 de diciembre de 1988 , p. 2; "Priistas y opositores toman siete alcaldías en Chiapas", El Día, 30 de diciembre de 1988 , p. 7.

55 Véase Leticia Hernández, "Siguen en poder de trabajadores, las instalaciones del ingenio Pujiltic", Excélsior, 17 de julio de 1986; Leticia Hernández, "Entregan los cañeros el ingenio Pujiltic; los dueños aceptaron todas sus peticiones", Excélsior, 18 de julio de 1986, p. 3 en los estados; Rodolfo López, "Ocupan campesinos una planta procesadora de cacahuate", Excélsior, 2 de octubre de 1986, p. 2 en los estados.

${ }^{56}$ Véase "Desalojo violento de cafeticultores, exigen el pago de 30 millones", Excélsior, 20 de diciembre de 1984, p. 9-D; "Fuera de peligro campesinos cenopistas", Excélsior, 22 de diciembre de 1984, p. 38-A.

${ }^{57}$ Leticia Hernández, "Se apoderan del local de ANACSA en Chiapas", Excélsior, 19 de diciembre de 1985.

${ }^{58}$ Véase "Violenta toma del sindicato de burócratas", Excélsior, 24 de julio de 1985, p. 2 en los estados.

59 Véase Leticia Hernández, "Cumple 3 días ocupado el edificio del SNTE en Tuxtla", Excélsior, 30 de mayo de 1988 , p. 2. 
porte colectivo ${ }^{60}$ y las vías públicas que, como el puente fronterizo con Guatemala, ${ }^{61}$ o la carretera Panamericana, ${ }^{62}$ además de su valor estratégico, resultaban indispensables para asegurar el flujo de personas y vehículos.

Por lo que se refiere a las manifestaciones, marchas y mítines, vale la pena señalar su tridimensionalidad al hacerse presentes en los planos local, estadual y nacional. Las ubicadas en este último ${ }^{63}$ estuvieron en general vinculadas con pliegos petitorios relativos a cuestiones agrarias y no satisfechas por las jurisdicciones territoriales respectivas (municipal y estadual). ${ }^{64}$ Pocas veces la presión ejercida

60 "Protestas contra el aumento de transporte", Excélsior, 5 de febrero de 1985, p. 28-A; "Secuestraron los estudiantes autobuses en Tuxtla", Excélsior, 27 de noviembre de 1985 , pp. 1 y 2 en los estados; "Amagan alumnos de la UNACh paralizar el transporte si no cesan al rector", Excélsior, 19 de enero de 1986.

${ }^{61}$ Véase Leticia Hernández, "Bloquearon el puente fronterizo los estudiantes de la Universidad de Chiapas", Excélsior, 11 de octubre de 1984, p. 7-D; Amet Flores Meneses, "De no resolverse demandas, bloqueará el magisterio un puente internacional", El Dia, 3 de marzo de 1985 , p. 5.

${ }_{62}$ Véase Francisco Núñez L., "La tropa normalizó la situación en Chiapas", Excélsior, 7 de marzo de 1979, p. 27-A; Porfirio Díaz López, "Libertad a los que bloquearon una carretera", Excélsior, 8 de marzo de 1979, p. 8-D; "Grupos del PAN, PRT y PST bloquearon el paso en la carretera Panamericana", El Día, 13 de mayo de 1986, p. 7 .

${ }^{63}$ En este rubro la marcha de Xi'Nich sería la más importante. Véase López, "Xi'Nich", 1992, p. 27; Correa, "Marcha", 1992, p. 21.

64 "Manifestación campesina contra la policía de Tuxtla Gutiérrez", Excélsior, 21 de septiembre de 1975, p. 17-A; Rodolfo López Sol, "Invaden el centro de Tapachula 1500 comerciantes que protestan", Excélsior, 22 de noviembre de 1983, p. 6-D; Leticia Hernández, "Marcha-mitín anuncian en Chiapas por dicha vía rindió los frutos que esperaban quienes recurrieron a ella; más bien, la respuesta casi crónica (sobre todo en los ámbitos local y estadual) fue la represión. ${ }^{65}$

Finalmente estarían las actividades delictivas del orden común que, en el caso de Chiapas, más de una vez se confundieron con protestas de tipo político. Si bien desde el punto de vista gubernamental las fronteras entre unas y otras eran difusas, conviene establecer que se trata de fenómenos diferenciados y que las primeras dan cuenta de una descomposición social no necesariamente vinculada con otras muestras de inconformidad descritas a lo largo de este trabajo.

De acuerdo con las estadísticas oficiales, el número de presuntos delincuentes registrados en los juzgados de primera instancia de los fueros federal y común aumentó entre 1985 y 1997 de 3592 a 5754 para el primer caso, y de 3335 a 4924 para el segundo. ${ }^{66}$ El mayor índice de crecimiento para el plano federal se explica en parte por la inclusión de rubros no considerados antes de 1990 (armas prohibidas, internamiento ilegal de inmigrantes, encubrimiento, ataque a las vías, contra la riqueza forestal, entre otros), pero de cualquier manera es de llamar la atención.

Durante el mismo lapso, el número de los presuntos responsables de robar pasó de 947 a 1 429, y los acusados de infringir lesiones a terceros disminuyó de 1186 a $971 .{ }^{67}$ Sería difícil recuperar

coordinadores de luchas populares", Excélsior, 15 de agosto de 1984, p. 9-D.

65 Véase Guillén, "Chiapas", 2003.

${ }^{66}$ Véase Cuaderno, 1998, pp. 3-4.

${ }^{67}$ lbid. 
el mundo de la delincuencia a partir de cifras y/o notas rojas, pero en ambas encontramos respaldo para la hipótesis de que las fronteras del mismo se ampliaron, sumándose al conjunto de desafíos que desde el gobierno debían de resolverse. ${ }^{68}$

Además de condiciones estructurales que afectaban a amplios sectores de la población, las situaciones de anomia fueron apoyadas por la irrupción de actores exógenos. $\mathrm{La}$ apertura de instalaciones para explotar petróleo y electricidad y el traslado de elementos policiacos y del ejército favorecieron el incremento de oportunidades para obtener recursos al margen de la ley.

Droga, prostitución, alcohol, robos, por mencionar sólo algunas de dichas opciones, rebasaban los espacios donde se concentraban desde empleados de PEMEX y de la CFE, hasta soldados rasos y policías; sin embargo, interesa destacar que este tipo de situaciones se agudizaron a raíz de que tales personajes se concentraron en territorios específicos de la entidad.

Ya en 1972 se denunciaba que el campamento que se había levantado en Raudales de Malpaso, para los trabajadores que construyeron la presa de Nezahualcóyotl, se había convertido en un pueblo sin ley. La población era de 5403 habitantes que vivían en casuchas de madera abigarradas de 173 lotes; había 54 cantinas, dos lupanares, 160 prostitutas y cinco policías. La única autoridad era un juez que dependía de la cabecera municipal de Tecpatán, a 60 kilómetros del lugar, desde donde los hermanos Joel, Miguel y Ramiro Conde establecían su

${ }^{68}$ Véase "Agitación en Chiapas", Excélsior, 5 de abril de 1976, p. 6-A; "Aumenta la violencia en Chiapas", Excélsior, 22 de noviembre de 1988, p. 4. predominio a partir del monopolio de la cerveza que poseían. ${ }^{69}$

Por lo que se refiere a la presencia del ejército, durante la década de los setenta el número de efectivos destacamentados en la entidad creció de manera considerable. Aunque sería difícil documentar esta afirmación con datos oficiales, se trata de un hecho que me tocó corroborar a simple vista; mi experiencia en la zona fronteriza fue que en 1973 los militares todavía pasaban desapercibidos, mientras que cinco años más tarde el panorama era totalmente distinto: retenes en la carretera, soldados que deambulaban por las ciudades $\mathrm{y}$ fronteras celosamente custodiadas.

En 1978 existía el proyecto de construir un eje carretero con aeropuertos paralelos que rodeara los yacimientos petroleros, las presas, la selva y los Altos. Además de cumplir las funciones formalmente asignadas y que básicamente se centraban en el resguardo de la frontera, el ejército recurría a simulacros de lucha antiguerrillera y a despliegues de su potencial para amedrentar a la población. ${ }^{70}$

A mediados de 1980 se denunciaban los atropellos que cometían las fuerzas públicas, quienes estaban aliadas con los finquetos y estaban encabezadas por el ejército; se hablaba de entre 7000 y 9000 efectivos de este último. ${ }^{71} \mathrm{~A}$ fines de ese año se organizó un simulacro de guerra que involucró a cinco estados del sureste (Yucatán, Chiapas, Quintana Roo, Tabasco y Campeche) y en el que participaron 43705 hombres movilizados en

${ }^{69}$ Véase Alejandro Iñigo, "Pueblo sin ley al lado de la presa Nezahualcóyotl", Excélsior, 5 de mayo de 1972, p. 14-A.

${ }^{70}$ Véase "Chiapas", 1978, pp. 20-22.

${ }^{71}$ Véase "Policías", 1980, pp. 10-13. 
un tiempo récord de 72 horas a lo largo de 2000 kilómetros. ${ }^{72}$

Los efectivos enviados a Chiapas formaban parte de la $7^{a}$ Región Militar, ${ }^{73}$ cuya comandancia se localizaba en Tuxtla Gutiérrez y que en 1993 estaba bajo el mando del general Miguel Ángel Godínez (jefe del Estado Mayor durante el sexenio de José López Portillo); como parte de ella aparecían la $31^{\text {a }}$ y la $36^{a}$ zonas militares con cuarteles en Tuxtla (para funciones más bien administrativas), San Cristóbal, Comitán y Tapachula. ${ }^{74}$

El número de elementos que integraban los cuarteles militares se volvió todavía más grande a partir de que el EZLN apareció en escena, ${ }^{75}$ pero ya había crecido notablemente en los años previos al conflicto, bajo el pretexto de resguardar la frontera de la guerra centroamericana y posteriormente del narcotráfico. En el fon-

${ }^{72}$ Véase Reyes, "Ocho", 1980.

${ }^{73} \mathrm{El}$ país está dividido en IX regiones militares y la vil cuenta con siete zonas militares: la 29 con sede en Veracruz, la 30 con sede en Tabasco, la 31 con sede en Chiapas, la 32 con sede en Yucatán, la 33 con sede en Campeche, la 34 con sede en Quintana Roo y la 36 con sede en Chiapas. El cuadro con todas las regiones y zonas militares puede verse en López, Guerra, 1996, p. 62.

${ }^{74}$ Entrevista a funcionario de la Procuraduría de Justicia del Estado, ciudad de México, diciembre de 1993.

${ }^{75}$ Para 1997 y citando como fuente a la Coordinación de Organismos no Gubernamentales por la Paz (CONPAZ) se hablaba de 40000 soldados (30\% del total de los militares del ejército mexicano) distribuidos en 70\% de los 111 municipios de Chiapas. En agosto de ese mismo año se mencionaba la presencia de 20000 soldados en 40 campamentos, cinco cuarteles y una zona militar concentrados en los municipios de Ocosingo, Las Margaritas y Altamirano. Véase Gómez, "Chiapas", 1998. do, la presencia de la fuerza pública federal dentro de los límites de Chiapas tenía también que ver con las necesidades de control de un aparato estatal al que las riendas se le escapaban de las manos, y que incluso planeaba utilizar los viejos caminos coloniales y construir un camino militar para resguardar el Centro y Norte de la entidad. ${ }^{76}$

Finalmente el tiro salió por la culata, y lejos de solucionar los problemas de gobernabilidad el ejército contribuyó a ahondarlos. ${ }^{77}$ Con la intervención federal se pretendía restaurar un orden que resultaba doblemente golpeado: por un lado, quedaban de manifiesto las limitaciones para resolver conflictos a través de las vías institucionales y, por el otro, se manifestaba la necesidad de recurrir a actores ajenos a la entidad que violentaban la ya de por sí erosionada dinámica local. ${ }^{78}$

\section{CONTROLAR O GOBERNAR}

De lo que hasta aquí se ha dicho se desprende que acciones aparentemente aisladas, y muchas veces con escasa o ninguna conexión entre sí, daban cuenta de un resquebrajamiento profundo. Los impactos de este último se manifestaban en la ausencia de legitimidad que por lo general acompañaba a las decisiones y actos

${ }^{76}$ Entrevista a funcionario chiapaneco realizada en la ciudad de México, octubre de 1993.

${ }^{77}$ Para un seguimiento puntual de los procesos que antes de 1994 se tradujeron en la virtual militarización de la entidad y de sus consecuencias sobre la vida local véase Guillén, "Chiapas", 2003.

${ }^{78}$ Respecto a las protestas contra la violencia y los abusos en los que por lo general incurría la fuerza pública véase Centro, Resumen, 1989, p. 29-31. 
de gobierno y en el estrecho margen de maniobra para resolver demandas que por el simple hecho de plantearse cuestionaban el statu quo.

Encuentros y desencuentros de las esferas societal y estatal iban más allá del tema de la gobernabilidad, pero era a través de ella que afloraban los niveles de erosión de un orden basado en patrones oligárquicos de intercambio político ${ }^{79} \mathrm{y}$ en estructuras socioeconómicas altamente polarizadas.

Durante la etapa a la que aquí hemos referido, los intentos por resanar fracturas de larga data y fisuras gestadas en el corto plazo incluían la alternativa de negociar y/o de impedir que los conflictos subieran de tono. Sin embargo, también se privilegió el uso de la fuerza, e independientemente de las veces que se llegó al enfrentamiento abierto ${ }^{80}$ el que se recurriera a ella contribuyó a desgastar la labor gubernamental.

La violencia como instrumento para resolver conflictos, incluso la institucional, deja siempre saldos negativos, pero cuan-

\footnotetext{
${ }^{79}$ A propósito del concepto de neoligarquización que se ha utilizado para caracterizar este tipo de patrones véase Ruiz, "Crisis", 1995.

${ }^{80}$ Entre 1974 y 1987 se registraron en las fuentes públicas de información 4731 casos de acciones represivas en Chiapas, acciones que abarcaban asesinatos; heridos y lesionados; detenidos y presos; intento de secuestro y secuestros; torturas; desaparecidos; atentados; expulsiones; intentos de violación y violaciones; agresiones físicas; intentos de desalojo y desalojos; robos de pertenencias y de documentación agraria; allanamientos de morada; saqueos de oficinas y archivos; acordonamientos policíacos; amenazas de muerte; represión a marchas y mítines; intimidación, y destrucción de viviendas, iglesias y escuelas. Véase Informe, 1989.
}

do además de ello existen escasos márgenes de legitimidad que respalden su empleo, lejos de ser una salida se convierte en fuente de nuevos desarreglos. Tal sería, a mi parecer, uno de los hilos que hilvanaron la historia reciente de Chiapas.

Desde tal perspectiva, quizá los términos más convenientes para definir la situación que se vivió en la entidad entre las décadas de los setenta y los noventa no sean déficit y crisis de gobernabilidad, pues la posibilidad de acceder a los estadios positivos de la tipología en la que se basan ambos conceptos (el ideal y el normal) nunca estuvo al alcance.

Si no existen elementos institucionales que aseguren el monopolio legítimo de la fuerza y el poder se ejerce sin reglas de acceso y distribución, lo primero que se tendría que consolidar son las relaciones básicas de gobierno. Las construcciones teóricas sobre la gobernabilidad provienen de países donde el término governability buscaba evaluar la eficiencia del actuar gubernamental (governance), pero la premisa era que este último cumplía los requisitos mínimos que le son inherentes dentro de un Estado moderno. ${ }^{81}$

Salta a la vista que la situación en Chiapas era muy distinta; los procesos tendientes a centralizar recursos y monopolizar la violencia física desde un espacio públicamente construido con dicho fin resultaban más bien precarios y la renuencia de las instancias gubernamentales para delimitar un ámbito autónomo respecto de los intereses privados se evidenciaba constantemente. ${ }^{82}$

81. Véase Camou, Desafíos, 2001, pp. 17-20.

${ }^{82}$ Un análisis detallado sobre las características y limitaciones del Estado en Chiapas puede encontrarse en Guillén, "¿Atisbos?”, 2001. 


\section{SECUENCIA}

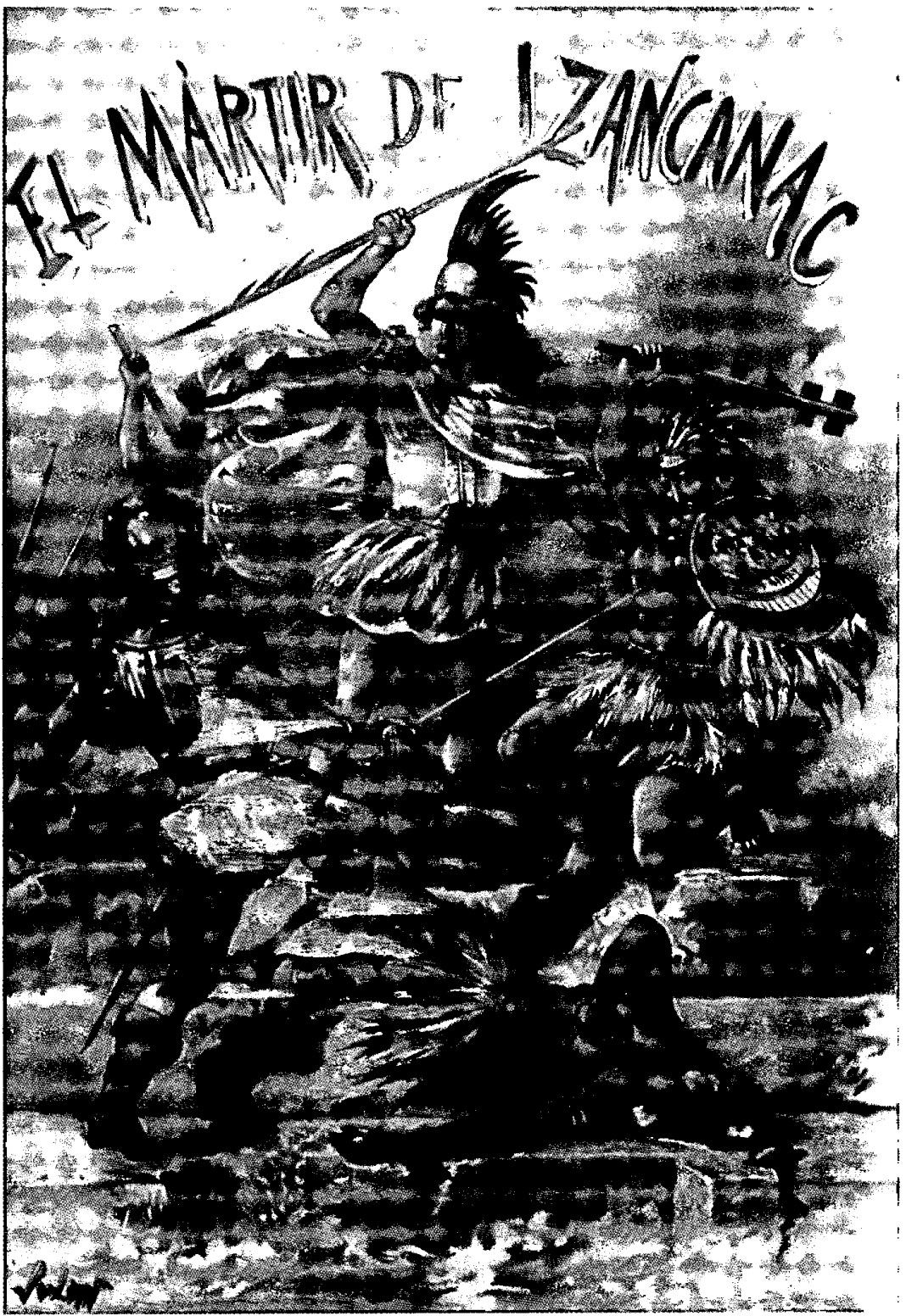


Ante la ausencia de reglas básicas de convivencia política, la relación entre gobernantes y gobernados estaba de antemano condenada a producir múltiples choques. Los límites institucionales para procesar un descontento en el que abrevaban añejas y nuevas demandas eran remontados desde la sociedad a través de tomas simbólicas y físicas de los espacios que se negaban (participación pública en mítines, marchas y manifestaciones, plantones, bloqueos, invasiones y demás variables a las que aquí me he referido).

En el otro extremo, el gobierno suplía su carencia de herramientas institucionales con redes informales que perdían eficiencia, ${ }^{83}$ y con el creciente uso de una fuerza que se empleaba por igual contra acciones que provenían de demandas justas (algunas veces legales y otras no), de oportunismos políticos o del abanico de combinaciones posibles que se abrían entre ambos polos.

A los ojos de los responsables del gobierno estadual, todas ellas entraban en un mismo paquete, pues de una u otra forma amenazaban las bases de ese orden que, más allá de sus inequidades, se les había encomendado reproducir. La idea que parece haber sustentado sus acciones estaba impregnada de tintes autoritarios y partía del principio de que gobernabilidad y democracia no se llevan bien.

La relación entre ambas variables es sumamente compleja, pues, en efecto, a primera vista, la libertad y la organización ciudadanas amplían el margen para los reclamos sociales, al tiempo que la toma pública de decisiones puede quedar tan acotada que acaba por perder eficiencia. ${ }^{84}$

${ }^{83}$ Véase Guillén, Chiapas, 1998, pp. 117-136.

${ }^{84}$ Véase Bobbio, Liberalismo, 1991, p. 104.
Sin embargo, su complejidad no es equivalente a antagonismo ${ }^{85}$ ni justifica que para ganar gobernabilidad se reduzcan espacios democráticos.

Cuando la incapacidad gubernamental para dar respuestas eficientes y legítimas a la sociedad se achaca a los avances y conquistas en torno a la democracia, se está invirtiendo el orden de los factores y, en este caso, alterando el producto. Al igual que el médico que receta cortar la cabeza para evitar que duela, la tendencia a endurecer la mano para reducir, o de plano eliminar, la interlocución con sociedades dinámicas y demandantes constituyen falsas soluciones a problemas reales.

Así, rebautizar la carga de solicitudes que debe procesar el aparato gubernamental añadiéndole un sufijo como sobre, implica calificar las expectativas sociales de excesivas. ${ }^{86}$ Éstas constituyen una sobrecarga porque no se les puede atender, pero en caso de ser legítimas tendrían que encontrarse los canales para hacerlo.

La construcción de verdaderos caminos hacia la gobernabilidad tiene que ir más allá del control sobre lo que la sociedad plantea como requerimientos; por

${ }^{85}$ Como bien dice Jesús Silva-Herzog Márquez "la gobernabilidad no está ligada a ningún tipo de régimen especial, no es patrimonio exclusivo de la democracia o del autoritarismo; la clave, en el fondo, me parece que es el diseño de las instituciones, la manera en que se vinculan los intereses sociales y los órganos de decisión y de deliberación política". Silva-Herzog, Puentes, 1998, pp. 8-9.

${ }^{86} \mathrm{El}$ planteamiento neoconservador en torno a la gobernabilidad "explicaba su posición negativa (la ingobernabilidad) como el producto de una sobrecarga de demandas a las que el Estado respondía con la expansión de sus servicios y de su intervención, provocando inevitablemente una crisis fiscal". Alcántara, Gobernabilidad, 1995, p. 33. 
principio de cuentas debe asegurar que las necesidades de la población se satisfagan (tarea imposible de llevar a la práctica si imperan altos niveles de pobreza y marginación). Asimismo requiere de un aparato institucional que respalde, $y$ en su caso legitime, las acciones públicas (tarea igualmente imposible si privan criterios oligárquicos de acceso y distribución del poder). En otras palabras, ni en Chiapas ni en ningún otro punto del planeta, el arte de gobernar se reduce a tapiar el camino de los gobernados.

\section{HEMEROGRAFÍA}

El Día.

El Universal.

Excélsior.

Uno más Uno.

\section{BIBLIOGRAFÍA}

- Agenda estadística de Chiapas 1992, Secretaría de Programación y Presupuesto del Estado, Tuxtla, 1992.

- Alcántara Sáez, Manuel, Gobernabilidad, crisis y cambio. Elementos para el estudio de la gobernabilidad de los sistemas polititicos en épocas de crisis y cambio, FCE, México, 1995.

-Arbós, Xavier y Salvador Giner, La gobernabilidad. Ciudadanía y democracia en la encrucijada mundial, Siglo XXI, España, 1993.

-Bobbio, Norberto, Liberalismo y democracia, FCE, México, 1991.

-Camou, Antonio, Gobernabilidad y democracia, IFE, México, 1995 (Cuadernos de Divulgación de la Cultura Democrática, 6).

(estudio preliminar y compilación), Los desafíos de la gobernabilidad, FLACSO/IISUNAM/Plaza y Valdés, México, 2001.
-XI Censo general de población y vivienda. Estados Unidos Mexicanos. Resumen general. Tabularios complementarios, INEGI, México, 1990.

-Centro de Información y Análisis de Chiapas, A. C., Resumen informativo, núm. 27, enero de 1989, San Cristóbal de las Casas, Chiapas.

-Constitución política y Código electoral del estado de Chiapas, Comisión Electoral del Estado de Chiapas, Tuxtla Gutiérrez, 1991.

-Correa, Guillermo, "El gobernador intenta llenar con represión el vacío de poder", Proceso, núm. 434, 23 de febrero de 1985, pp. 29-30.

—, "La marcha de Xi'Nich: 1100 kilómetros para lograr promesas", Proceso, núm. 808, 25 de abril de 1992, p. 21.

-Cruz, José Antonio, Absalón Castellanos y terratenientes: un análisis coyuntural, Universidad Autónoma de Chiapas, México, 1982.

-Cuaderno de estadísticas judiciales del estado de Cbiapas, INEGI, México, 1998, t. 1.

-"Chiapas. Del simulacro y la dura realidad", Proceso, núm. 76, 17 de abril de 1978.

-Gall, Olivia, "Los elementos histórico-estructurales del racismo en Chiapas" en Alicia Castellanos Guerrero y Juan Manuel Sandoval (coords.), Nación, racismo e identidad, Nuestro Tiempo, México, 1998 (Colección Los Grandes Problemas Nacionales), pp. 162-179. (coord.), Chiapas: sociedad, economía, interculturalidad y polititia, UNAM/CEICH, México, 2001.

-García de León, Antonio, Resistencia y utopía. Memorial de agravios y crónica de revueltas y profecías acaecidas en la provincia de Chiapas durante los últimos quinientos años de su bistoria, Era, México, 1985, 2 vols.

-Gómez Tagle, Silvia, "Chiapas: la militarización como forma de gobierno", LASA-Forzm, vol. XXxix, núm. 3, 1998.

-Guillén, Diana (coord.), Chiapas: una modernidad inconclusa, Instituto Mora, México, 1995. 
, Chiapas 1973-1993. Mediaciones, política e institucionalidad, Instituto Mora, México, 1998.

"¿Atisbos de una clase política?" en Olivia Gall (coord.), Chiapas: sociedad, economía, interculturalidad y política, UNAM/CEICH, México, 2001.

- "Chiapas: las distintas caras de la violencia" en Diana Guillén (coord.), Chiapas: rupturas y continuidades de una sociedad fragmentada, Instituto Mora, México, 2003.

(coord.), Chiapas: mpturas y continuidades de una sociedad fragmentada, Instituto Mora, México, 2003.

-Harvey, Neil, La rebelión en Chiapas. La lucha por la tierra y la democracia, Era, México, 2000 (Colección Problemas de México).

-Informe del Centro de Derechos Humanos "Fray Bartolomé de las Casas", núm. 1, marzo de 1989.

-López A., Martha Patricia, La guerra de baja intensidad en México, Plaza y Valdés, México, 1996.

-López Narváez, Froylán M., "Xi’Nich, drama chiapaneco", Procesa, núm. 804, 30 de marzo de 1992, p. 27.

-Mendoza Ramírez, Martha Patricia, "La intervención gubernamental en la selva Lacandona" en Diana Guillén (coord.), Chiapas: una modernidad inconclusa, Instituto Mora, México, 1995.

- "Policías y tropas en Chiapas, al servicio de finqueros y comerciantes", Proceso, núm. 197, 21 de julio de 1980.

-Reyes Fuentes, José Mario, "Ocho guatemaltecos, observadores de las maniobras del ejército mexicano contra el invasor antillano", Proceso, núm. 218, 15 de diciembre de 1980.

-Rodríguez, Erwin, "En torno a los hilos delgados de la frontera sur: la agudización de los problemas agrarios en Chiapas durante la década de los ochenta" en Luis Hernández Palacios y Juan Manuel Sandoval (comps.), El redescubrimiento de la frontera sur, Universidad Autónoma de Zacatecas/UAM, México, 1989.

-Ruiz Contardo, Eduardo, "Crisis, descomposición y neoligarquización del sistema político en América Latina", Política y Cultura, UAMXochimilco, núm. 5, otoño de 1995.

-Rus, Jan, "La Comunidad Revolucionaria Institucional: la subversión del gobierno indígena en los Altos de Chiapas, 1936-1968" en Juan Pedro Viqueira y Mario Humberto Ruz (eds.), Chiapas, los rumbos de otra bistoria, UNAM/CIESAS/ CEMCA/Universidad de Guadalajara, México, 1995.

-Salazar, Hilda y Silvia Whizar, "Participación ciudadana y petróleo", El Cotidiano, núm. 91, septiembre-octubre de 1998, pp. 55-64.

-"Se multiplican los males en Chiapas y Castellanos sólo reprime”, Proceso, núm. 485, 27 de enero de 1986, pp. 22-24.

-Silva-Herzog Márquez, Jesús, Las puentes de la gobernabilidad, H. LIII Legislatura del Estado de México, Toluca, 1998 (Serie Conferencia, 3).

-Stolowicz, Beatriz, "Gobernabilidad o democracia: los usos conservadores de la política", Política y Cultura, UAM-Xochimilco, núm. 8, primavera de 1997, pp. 187-213.

-Villafuerte Solís, Daniel et al., La tierra en Cbiapas. Viejos problemas nuevos, Plaza y Valdés, México, 1999.

-Viqueira, Juan Pedro y Mario Humberto Ruz (eds.), Chiapas, los rumbos de otra bistoria, UNAM/CIESAS/CEMCA/Universidad de Guadalajara, México, 1995. 